\title{
Iron-Ethylenediaminetetraacetic acid (EDTA)-Catalyzed Superoxide Dismutation Revisited: An Explanation of Why the Dismutase Activity of Fe-EDTA Cannot Be Detected in the Cytochrome c/Xanthine Oxidase Assay System ${ }^{1}$
}

\author{
C. BULL,* J. A. FEE, ${ }^{* 2}$ P. O’NEILL, $\dagger$ AND E. M. FIELDEN $\dagger$ \\ *Biophysics Research Division and Department of Biological Chemistry, The University of Michigan, \\ Ann Arbor, Michigan 48109, and the †Division of Physics, Institute of Cancer Research, \\ Clifton Avenue, Surrey SM2 $2 P X$, United Kingdom
}

Received September 1, 1981, and in revised form January 9, 1982

The recent assertion of J. Diguiseppi and I. Fridovich (1980, Arch. Biochem. Biophys. 203, 145-150) that Fe-EDTA does not catalyze superoxide dismutation is disputed. By directly observing superoxide generated during pulse radiolysis, we have confirmed the results of a previous study (G. J. McClune, J. A. Fee, G. A. McClusky, and J. T. Groves, 1977, J. Amer. Chem. Soc. 99, 5220-5222) which concluded that Fe-EDTA catalyzed superoxide dismutation. We also demonstrate that the reaction of $\mathrm{Fe}$ (II)-EDTA, formed during catalyzed superoxide dismutation, with cytochrome $c$, the probe molecule in the cytochrome $c / x a n t h i n e$ oxidase/xanthine assay system for superoxide dismutase activity, is sufficiently rapid (H. L. Hodges, R. A. Holwerda, and H. B. Gray, 1974, J. Amer. Chem. Soc. 96, 3132-3137) to obscure the weak catalysis of superoxide dismutation by Fe-EDTA.

Recently, Diguiseppi and Fridovich (1) reported that the weak superoxide dismutase activity of Fe-EDTA (ethylenediaminetetraacetic acid) complexes (2) could not be demonstrated in widely used assay systems for the measurement of superoxide dismutase activity and concluded that Fe-EDTA complexes did not catalytically scavenge $\mathrm{O}_{2}^{-}$. Since this conclusion contradicted earlier studies in which catalysis was detected by direct spectral observation of superoxide $(2,3)$, we have investigated the origin of the discrepancy

\footnotetext{
${ }^{1}$ Supported by a grant from the USPHS, GM 21519 (J.A.F.), and by grants to the Division of Physics, Institute of Cancer Research, from the Medical Research Council, and the Cancer Research Campaign (E.M.F.).

${ }^{2}$ Address inquiries to this author: Biophysics Research Division, 2200 Bonisteel Blvd., Ann Arbor, Mich. 48109.
}

between the two experimental systems. In this note, we confirm that Fe-EDTA is a catalyst of superoxide dismutation, a possibility first suggested by Halliwell (4). And, by using numerical solutions to the set of differential equations describing the generally accepted chemistry of the cytochrome $c / x a n t h i n e$ oxidase assay system (5), we have shown that it is not possible to observe the catalysis in this assay system because $\mathrm{Fe}$ (II)-EDTA, formed during Fe-EDTA-catalyzed superoxide dismutation, rapidly reduces cytochrome $c$.

\section{MATERIALS AND METHODS}

The 4.3-MeV linear accelerator and ancillaries have previously been described (6). All solutions were prepared using triply distilled water and contained $0.1 \mathrm{M}$ ethanol, $0.1 \mathrm{mM}$ EDTA, and were saturated with $\mathrm{O}_{2}$. Solutions contained in a quartz cell of $0.7-$ or 2$\mathrm{cm}$ optical path length were irradiated with electron pulses of $1.6 \mu \mathrm{s}$ duration. In this system the primary 


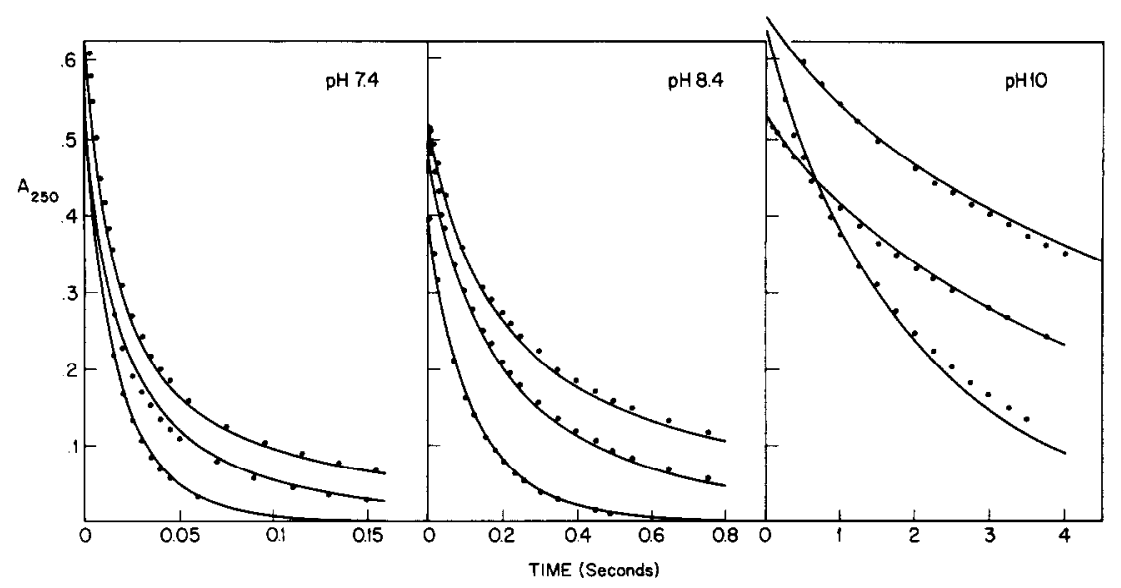

FIG. 1. The influence of $\mathrm{pH}$ and Fe-EDTA on the decay rate of $\mathrm{O}_{2}^{-}$. The experimental data (points) were taken at $\mathrm{pH} 7.4,8.4$, and 10.0 in the presence of only contaminating levels of Fe-EDTA ( 2 $\mu \mathrm{M}$ Fe, top curve; $7 \mu \mathrm{M}$ Fe-EDTA, middle curve; and $20 \mu \mathrm{M}$ Fe-EDTA, bottom curve). The buffers used were: $10 \mathrm{mM}$ phosphate, $\mathrm{pH} \mathrm{7.4;} \mathrm{and} 10 \mathrm{mM}$ pyrophosphate, $\mathrm{pH} 8.4$ and 10.0. The solid lines are simulations using the following rate constants for the reactions shown in Table $\mathrm{I}$ at $\mathrm{pH}$ 7.4, 8.4, and 10.0, respectively: Reaction $2\left(\mathrm{M}^{-1} \mathrm{~s}^{-1}\right) 1.6 \times 10^{5}, 1.6 \times 10^{4}, 6.1 \times 10^{2}$; Reaction $4\left(\mathrm{M}^{-1} \mathrm{~s}^{-1}\right)$; $1.2 \times 10^{6}, 1.5 \times 10^{5}, 1.2 \times 10^{4}$; Reaction $5\left(\mathrm{M}^{-1} \mathrm{~s}^{-1}\right) 2 \times 10^{6}, 2 \times 10^{6}, 2 \times 10^{6}$; and Reaction $6\left(\mathrm{~s}^{-1}\right) 1250$, 125,4 . The $\mathrm{O}_{2}^{-}$was created radiolytically in a $2-\mathrm{cm}$ observation cell at an ambient temperature of $20^{\circ} \mathrm{C}$.

radicals produced on irradiation of water are converted into $\mathrm{O}_{2}^{-}$, and the absorbance of $\mathrm{O}_{2}^{-}$at $250 \mathrm{~nm}$ $\left(\epsilon=2000 \mathrm{M}^{-1} \mathrm{~cm}^{-1}\right)$ was used to follow its decay. $\mathrm{Cy}$ tochrome $c$ from horse heart (Type III) was supplied by Sigma and all other reagents were of AnalaR grade. The formation of reduced cytochrome $c$ was monitored at $550 \mathrm{~nm}$ using a bandwidth of $2.5 \mathrm{~nm}$ $\left(\Delta \epsilon_{550}^{\text {eff }}=15,300 \mathrm{M}^{-1} \mathrm{~cm}^{-1}\right.$ ). Optical filters were used, when necessary, to minimize photochemical effects. The reactions were simulated on a Nova II minicomputer using the classical fourth-order Runge-Kutta procedure (7).

\section{RESULTS AND DISCUSSION}

Figure 1 contains decay curves for superoxide in the absence of added iron and in the presence of Fe-EDTA at pH 7.4, 8.4, and 10.0. The initial concentration of $\mathrm{O}_{2}^{-}$ in these experiments ranged from 100 to $160 \mu \mathrm{M}$ while the concentration of $\mathrm{Fe}-$ EDTA was at least fivefold lower. The fact that the rate of decay of $\mathrm{O}_{2}^{-}$is enhanced by the presence of substoichiometric amounts of Fe-EDTA is a clear demonstration of catalysis. The decay curves of $\mathrm{O}_{2}^{-}$are approximately second order at high $\mathrm{O}_{2}^{-}$concentration and first order (log-linear) at very low $\mathrm{O}_{2}^{-}$concentration as ex-

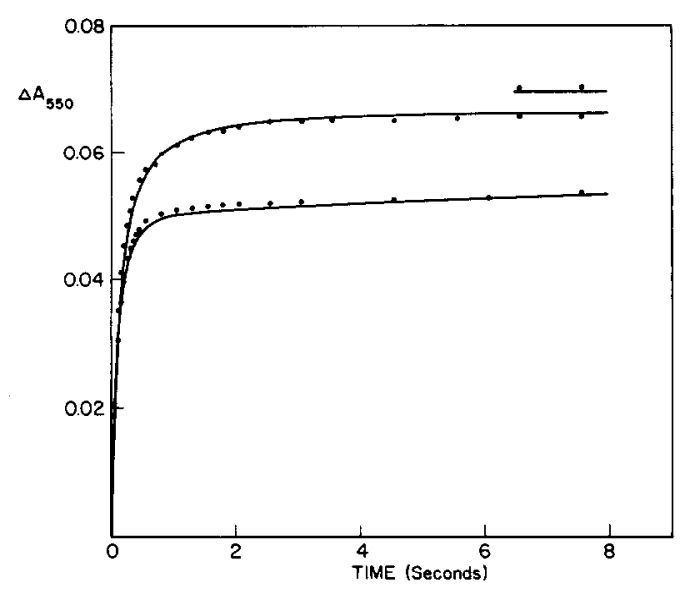

FIG. 2. Reduction of cytochrome $c$ by $\mathrm{O}_{2}^{-}$at $\mathrm{pH} 7.8$ (10 $\mathrm{mM}$ phosphate) in the presence and absence of added $\mathrm{Fe}$ (III)-EDTA. Experimental data are indicated by the points and the lines are computed. The uppermost trace (short line) corresponds to full reduction of the $6.5 \mu \mathrm{M}$ cytochrome $c$ used in the experiment. This was achieved by using two sequential pulses each generating $12 \mu \mathrm{M} \mathrm{O} \mathrm{O}_{2}^{-}$. The middle trace resulted from an initial condition of $6.5 \mu \mathrm{M}$ oxidized cytochrome and $12 \mu \mathrm{M} \mathrm{O}_{2}^{-}$in the absence of added FeEDTA. The bottom curve was generated from an initial mixture of $6.5 \mu \mathrm{M}$ oxidized cytochrome $c, 12 \mu \mathrm{M}$ $\mathrm{O}_{2}^{-}$and $11 \mu \mathrm{M} \mathrm{Fe}$ (III)-EDTA. The addition of a small amount of catalase had no effect on the kinetic behavior during the time of these experiments. 
TABLE I

Reactions Relevant to the Detection of Fe-EDTA-Catalyzed Dismutation in THE CYTOCHROME $c /$ XANTHINE OXIDASE SYSTEM $^{a}$

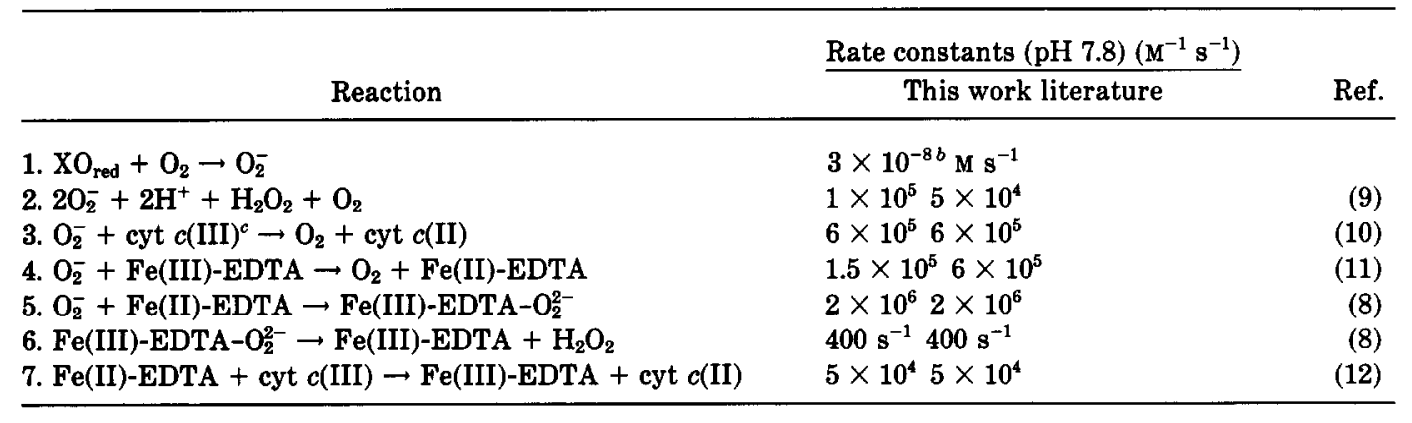

${ }^{a}$ Rate constants taken from the indicated references were interpolated to $\mathrm{pH} 7.8$, the condition used in Ref. (1). Rate constants at other $\mathrm{pH}$ 's are given in the legends to the figures. No reactions of $\mathrm{H}_{2} \mathrm{O}_{2}$ were considered, this being equivalent to adding catalase to the reaction mixture.

${ }^{b}$ We have set the velocity of this reaction to account for the rate of cytochrome $c$ reduction reported in Ref. (1).

c cyt $c$, Cytochrome $c$.

pected for dismutation proceeding by both an uncatalyzed and a catalyzed process. Since graphical analysis of such a system is difficult, we have numerically simulated the decay curves. The solid lines shown in Fig. 1 were computed using a step size of $2 \mathrm{~ms}$ and rate constants gathered from the literature for the previously proposed mechanism of this catalysis $(2,8)$. There is an excellent correlation between experiment and theory.

Turning now to the cytochrome $c / \mathrm{Fe}$ EDTA system, the points in Fig. 2 show the kinetic behavior of cytochrome $c$ reduction by a twofold excess of $\mathrm{O}_{2}^{-}$. In the absence of Fe-EDTA 90\% of the cytochrome $c$ becomes reduced, while the rest of the electrons of the initial $\mathrm{O}_{2}^{-}$are lost via dismutation to $\mathrm{O}_{2}$ and $\mathrm{H}_{2} \mathrm{O}_{2}$. In the presence of Fe-EDTA, reduction of cytochrome $c$ is biphasic and less cytochrome $c$ is reduced (lower trace): The initial phase ends sooner and is followed by a much smaller and slower phase which is complete within $15 \mathrm{sc}$.

The simulations (solid lines) allow us to explain what is occurring in this complicated reaction mixture. The middle curve of Fig. 2 was computed using the constants of Table I and assuming the presence of $2 \mu \mathrm{M}$ adventitious $\mathrm{Fe}$ as $\mathrm{Fe}$ (III)-EDTA. Similarly, the lower curve was computed for the presence of $13 \mu \mathrm{M} F($ III)-EDTA. The rather precise correlation between theory and experiment shows that no reactions other than those in Table I are necessary to explain this behavior, and it allows the following qualitative interpretation: The initial, rapid reduction of cytochrome $c$ is due to Reaction 3. The incomplete reduction of cytochrome $c$ by the initial twofold excess of $\mathrm{O}_{2}^{-}$over cytochrome is due to competition by Reaction 2 for $\mathrm{O}_{2}^{-}$. In the presence of Fe-EDTA, one has additional competition for superoxide by Reactions 4 and $5 .^{3}$ Further, some Fe(II)-EDTA accumulates (data not shown), and this reduces cytochrome $c$ in the second phase (lower curve). ${ }^{4}$ The diminished, overall reduction of cytochrome $c$ by $\mathrm{O}_{2}^{-}$in the presence of Fe-EDTA is due to the catalytic cycle (Reactions 4-6). Why is this catalysis not observed in the cytochrome $c /$ xanthine oxidase assay system?

This assay relys on the ability of super-

\footnotetext{
${ }^{3}$ Traces similar to those of Fig. 1 were measured in the presence of cytochrome $c$, and the $\mathrm{O}_{2}^{-}$was shown to decay more rapidly in the presence of $\mathrm{Fe}-$ EDTA. These data were quantitatively consistent with all the other observations.

${ }^{4}$ It must be emphasized that, under these conditions, $\mathrm{Fe}$ (II)-EDTA is both thermodynamically (13, 14) and kinetically (Table I) a favorable reductant of cytochrome $c$.
} 


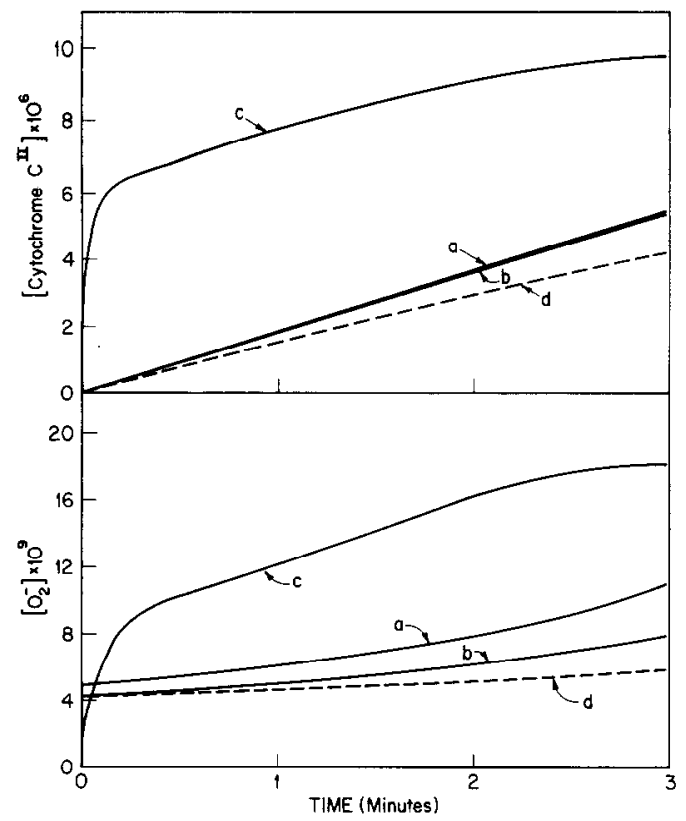

FIG. 3. Computer simulation of the cytochrome $c /$ xanthine oxidase assay system for superoxide dismutase activity. The upper panel demonstrates the reduction of the cytochrome, and the bottom panel shows the concentration of $\mathrm{O}_{2}^{-}$during the assay. The rate constants given in Table I were used with Reactions 5 and 6 combined (see text), the initial concentration of oxidized cytochrome was $10 \mu \mathrm{M}$, and the $\mathrm{O}_{2}^{-}$production was fixed at $3 \times 10^{-8} \mathrm{M} \mathrm{s}^{-1}$ to approximate the rate of cytochrome $c$ reduction observed in Ref. (1). Curves a: Computation of the standard assay system in the absence of added Fe-EDTA. Curves b: Standard assay system with an initial concentration of $6.4 \mu \mathrm{M}$ Fe(III)-EDTA. Curves c: Standard assay system with an initial concentration of $6.4 \mu \mathrm{M}$ Fe(II)-EDTA. Curves d (dashed lines): Same conditions as curves $\mathrm{b}$ but assuming no reaction between Fe(II)-EDTA and cytochrome $c\left(k_{7}=0\right)$.

oxide dismutases to prevent electron transfer from superoxide, formed in Reaction 1 of Table I, to cytochrome $c$. Since we know the rate constants for all the reactions in Table I it is possible to calculate the behavior of the assay system, and the full set of expressions was simulated out to $60 \mathrm{~s}$ using a step size of $2 \mathrm{~ms}$. By combining Reactions 5 and 6 in to a single reaction $^{5}$ having the rate constant of Reac-

\footnotetext{
${ }^{5}$ The results of the first simulation showed that the steady state concentration of $\mathrm{O}_{2}^{-}$was generally less than $10 \mathrm{nM}$ and that of the peroxo complex less than $10 \mathrm{pM}$; this required $1 \mathrm{~h}$ of computation time.
}

tion 5, the "stiffness" (8) of the numerical solution is reduced, and the simulation of the assay system was carried out to $3 \mathrm{~min}$ using a 10-ms step size.

Curves $a, b$, and $c$ of Fig. 3, which correspond closely to experiments described by Diguiseppi and Fridovich (1), match the observed results very well. In the presence of an initial concentration of $6.4 \mu \mathrm{M} \mathrm{Fe}$ (III)EDTA, the rate of cytochrome $c$ reduction is lowered by only $4 \%$, an amount which would not be experimentally distinguishable from the system lacking Fe-EDTA. In the presence of an initial concentration of $6.4 \mu \mathrm{M} \mathrm{Fe}$ (II)-EDTA there is a fairly rapid reduction of cytochrome $c$, as was observed (1), which is primarily due to Reaction 7. It is the occurrence of this reaction which does not allow the weak dismutase activity of Fe-EDTA to be observed in this assay system. This conclusion is illustrated in curve $d$ of Fig. 3 by arbitrarily setting the rate of Reaction 7 to zero. In this hypothetical system, the influence of Reactions 4-6 is clearly evident. Another important conclusion which can be drawn from these calculations is that, in the absence of catalysts of superoxide dismutation and under the described conditions of assay (1), greater than $99.9 \%$ of the superoxide formed by reaction of xanthine oxidase with oxygen during the first 3 min of reaction is trapped by the cytochrome. This may be of importance in the quantification of superoxide in complex biological systems.

The results presented above point out a potential pitfall in any steady-state assay for superoxide dismutase activity: Since metal-ion-catalyzed superoxide dismutation appears generally to occur by means of cyclic oxidation-reduction of the metal (15) it is imperative that the catalyst not interact with the probe molecule (in this case cytochrome $c$ ). This empha-

Since the decay rate of the peroxo complex is at least 100 times greater than the rate of its formation when the $\left[\mathrm{O}_{2}^{-}\right]<20 \mathrm{nM}$, Reactions 5 and 6 can be combined. These two sets of expressions gave identical results, and a simulation out to $3 \mathrm{~min}$ with the abbreviated set required only $10 \mathrm{~min}$. 
sizes that the direct methods of observing superoxide dismutase activity are to be preferred whenever possible and that great caution must be exercised in deriving mechanistic information from indirect assays.

\section{ACKNOWLEDGMENT}

We acknowledge the expert assistance of Dr. Gregory J. McClune in writing the computer program for the kinetic simulations.

\section{REFERENCES}

1. DiguisePPI, J., AND Fridovich, I. (1980) Arch. Biochem. Biophys. 208, 145-150.

2. MCClune, G. J., FEe, J. A., McClusky, G. A., AND Groves, J. T. (1977) J. Amer. Chem. Soc. 99, 5220-5222.

3. CARLE, C. I. (1976) Ph.D. Thesis, University of London.

4. HALLIWELL, B. (1976) FEBS Lett. 67, 294-296.

5. MCCORD, J. M., AND FrIDOviCH, I. (1969) J. Biol. Chem. 244, 1049-6055.
6. Mcadam, M. E., Fox, R. A., Lavelle, F., AND FIELDEN, E. M. (1977) Biochem. J. 165, 71-79.

7. GEAR, C. W. (1971) Numerical Initial Value Problems in Ordinary Differential Equations, Prentice-Hall, Engelwood Cliffs, N. J.

8. MCClune, G. J. (1979) Ph.D. Thesis, University of Michigan (available from University Microfilms Inc., Ann Arbor, Mich.).

9. BIELSKI, B. H. J., AND AlLEN, A. O. (1977) J. Phys. Chem. 81, 1048-1050.

10. Simic, M. G., TAUB, I. A., TOCCI, J., AND HURWITZ, P. A. (1975) Biochem. Biophys. Res. Commun. 62, 161-167.

11. ILAN, Y. A., AND CZAPSKI, G. (1977) Biochim. Biophys. Acta 498, 386-394.

12. HODGES, H. L., HolwERDA, R. A., AND GRAY, H. B. (1974) J. Amer. Chem. Soc. 96, 3132-3137.

13. SCHWARZENRACH, G., AND Heiller, J. (1951) Helv. Chim. Acta 34, 576-591.

14. PAUL, K-.G. (1947) Arch. Biochem. 12, 441-450.

15. FEE, J. A., AND MCCLuNE, G. J. (1978) in Mechanisms of Oxidizing Enzymes (Singer, T. P. and Ondarza, R. N., eds.), pp. 273-283, Elsevier/North-Holland, Amsterdam. 